\title{
Climatic impacts on water resources in a tropical catchment in Uganda and adaptation measures proposed by resident stakeholders
}

\author{
Bano Mehdi $^{1}$ (D) Julie Dekens ${ }^{2} \cdot$ Mathew Herrnegger $^{1}$ (D)
}

Received: 28 April 2020 / Accepted: 5 January 2021/ Published online: 20 January 2021

(C) The Author(s) 2021

\begin{abstract}
The Ruhezamyenda catchment in Uganda includes a unique lake, Lake Bunyonyi, and is threatened by increasing social and environmental pressures. The COSERO hydrological model was used to assess the impact of climate change on future surface runoff and evapotranspiration in the Lake Bunyonyi catchment $\left(381 \mathrm{~km}^{2}\right)$. The model was forced with an ensemble of CMIP5 global climate model (GCM) simulations for the mid-term future (2041-2070) and for the far future (2071-2100), each with RCP4.5 and RCP8.5. In the Ruhezamyenda catchment, compared to 1971-2000, the median of all GCMs (for both RCPs) showed the mean monthly air temperature to increase by approximately 1.5 to $3.0^{\circ} \mathrm{C}$ in the mid-term future and by roughly 2.0 to $4.5^{\circ} \mathrm{C}$ in the far future. The mean annual precipitation is generally projected to increase, with future changes between -25 and $+75 \%$ (RCP8.5). AET in the Lake Bunyonyi catchment was simulated to increase for the future by approximately $+8 \mathrm{~mm} /$ month in the median of all GCMs for RCP8.5 for the far future. The runoff for future periods showed much uncertainty, but with an overall increasing trend. A combination of no-regrets adaptation options in the five categories of: governance; communication and capacity development; water, soil, land management and livelihoods improvement; data management; and research, was identified and validated with stakeholders, who also identified additional adaptation actions based on the model results. This study contributes to improving scientific knowledge on the impacts of climate change on water resources in Uganda with the purpose to support adaptation.
\end{abstract}

Keywords Lake Bunyonyi · Ruhezamyenda $\cdot$ Climate change adaptation · COSERO · Hydrological modelling $\cdot$ Stakeholder workshop

Bano Mehdi

bano.mehdi@boku.ac.at

1 University of Natural Resources and Life Sciences, Vienna (BOKU), Institute for Hydrology and Water Management, Vienna, Austria

2 International Institute for Sustainable Development (IISD), Secretariat for the NAP Global Network, Winnipeg, Manitoba, Canada 


\section{Introduction}

The Ruhezamyenda catchment is at risk due to several factors, including increasing population pressure, water scarcity, loss of wetlands, deforestation and soil erosion. The average population density of the districts of Kisoro and Kabale located in the catchment is the second highest in Uganda, after Kampala (Geo-Ref.net n.d.).

Lake Bunyonyi lies in the Ruhezamyenda catchment and is a deep freshwater lake that provides not only important ecological habitats for unique fish, birds (including the threatened grey crowned crane) and other species, but also local economic opportunities, such as papyrus harvesting and wetland crop farming (Maclean et al. 2003). Lake Bunyonyi's watershed $\left(381 \mathrm{~km}^{2}\right.$ ) comprises $53 \%$ of the Ruhezamyenda catchment and constitutes a vital part of the natural, environmental, socioeconomic and cultural aspects of the region. From 1987 to 2014, the wetland areas around the lake declined by 3.8\% (Kizza et al. 2017) mainly because of conversion into agricultural land (Carswell 2002; Kizza et al. 2017), for example, into eucalyptus plantations (Crerar and Akurut 2017), or due to the over-harvesting of papyrus (Maclean et al. 2003). Climate change may alter further water balance components of the catchment.

For Uganda, the mean annual temperature changes from global climate models (GCMs) simulate increases of 1 to $1.3{ }^{\circ} \mathrm{C}$ by 2060 s and 1.4 to $4.9{ }^{\circ} \mathrm{C}$ by $2090 \mathrm{~s}$ (McSweeney et al. $2010 \mathrm{a}, \mathrm{b}$ ), which is consistent with ranges reported for eastern Africa by the IPCC (Christensen et al. 2013; Niang et al. 2014) and with a review (Adhikari et al. 2016) reporting increases of 0.6 to $3.4{ }^{\circ} \mathrm{C}(2060 \mathrm{~s})$ and 1.3 to $5.5^{\circ} \mathrm{C}(2090 \mathrm{~s})$.

Future precipitation amounts and timings are less certain. GCMs show overall agreement for Uganda by 2090s with mean annual precipitation changes of -8 to $+46 \%$ that are largest during the short rainy season (OND) and show consistent increases in the proportion of rain falling as heavy events; increases in maximum rainfall up to $27 \mathrm{~mm}$ in 1-day events, and up to $37 \mathrm{~mm}$ in 5-day events, whereby the largest increases occur in both rainy seasons (MAM and OND) (McSweeney et al. 2010a, b). The rainfall variability is also projected to increase between the wet and dry seasons (Collins et al. 2013).

For eastern Africa, the GCMs show future increases in rainfall, particularly from September to December, including increases in extreme rainfall, but unclear signals surrounding rainfall in MAM (Christensen et al. 2013). Drought event frequency and duration from GCMs are generally projected to decrease for Uganda (Haile et al. 2020). However, at the smaller scale, the RCMs suggest drying over most parts of Uganda by the end of the twenty-first century (Niang et al. 2014). The frequency of hot and dry years has already augmented between 1961 and 2005 due to increasing regional temperatures, and despite climate model predictions of greater regional precipitation, this trend is likely to continue (Coffel et al. 2019).

The simulated future runoff for East Africa depends largely on the precipitation changes. Although there are substantial uncertainty and variability in the spatial and temporal distribution of these changes, runoff is generally projected to increase (Adhikari et al. 2016). In the Mitano catchment located to the north of the Ruhezamyenda catchment, one RCM simulation (2070-2100 with A2 emissions scenario) showing mean annual precipitation increases of $14 \%$ (and increased rainfall intensity) and PET increases of 53\% was applied to a soil moisture balance model and showed increased mean annual runoff of $137 \%$, occurring mostly during the second rainy season with increased risks of floods and soil erosion (Mileham et al. 2009). Overall, East Africa will experience more heavy precipitation and flooding (Adhikari et al. 2016). 
River discharge will be altered in the future and will be more variable (temporally and spatially). Lake water levels that depend on discharge and on precipitation may decrease due to higher ET, despite receiving greater rainfall (Natugonza et al. 2016). The projections for ET are shown to increase for eastern Africa, e.g. up to $0.6 \mathrm{~mm} /$ day (Collins et al. 2013).

The Government of Uganda $(\mathrm{GoU})$ has identified the water resources sector as one of the country's priority sectors for climate adaptation. Water management planning in Uganda is based on the principle of integrated water resources management using a catchment-based approach. This is administered by assigning water resources development and management functions to four water management zones (WMZs), which are further divided into water catchments. Catchment management plans (CMPs) are a central participatory tool to help balance the growing water demands of different users with the limited resources available and to guide the implementation of water management measures to protect and conserve the catchments within each WMZ. So far, climate change concerns have not been systematically addressed in the development of the CMP. However, the catchment management planning guidelines were revised in 2016/2017 to integrate climate change concerns. The Ruhezamyenda CMP report (Rukundo 2015) stresses that hydrological modelling through simulations with data from the river systems within the Ruhezamyenda catchment is required to provide accurate results for informed decision-making.

Limited modelling studies to manage water in the future have been undertaken in Uganda. Using the AquaCrop model, soil mulching was found to be an effective adaptation strategy to reduce ET loss and thereby improve maize yields (Kikoyo and Norbert 2016). The SWAT hydrological model was used to evaluate future impacts on wetlands, whereby the adoption of conservation land management strategies in inland valleys effectively reduced peak flows and runoff (Gabiri et al. 2009).

In Uganda, adaptation strategies have rarely been implemented (Bagamba et al. 2012; Kikoyo and Norbert 2016). Particularly, the smallholder farmers in southwestern Uganda are vulnerable, where over $70 \%$ of smallholders may be adversely affected by climate change due to the reduced farm size and limited livelihood alternatives (Bagamba et al. 2012; Call et al. 2019). Long-term above-average temperatures in Uganda have caused a decrease in agricultural productivity and in the diversity of smallholder farms (Call et al. 2019).

In this study, we define climate change adaptation measures in the Ruhezamyenda by the following two objectives: (1) assess the impacts of future climate simulations on the water resources in the Lake Bunyonyi catchment and quantify the future changes and (2) through a participatory process with resident stakeholders determine possible climate change adaptation options for the catchment, based on the assessment results.

\section{Method}

\subsection{Site description}

The Ruhezamyenda catchment $\left(722 \mathrm{~km}^{2}\right)$ lies in southwestern Uganda and is part of the White Nile River Basin. The catchment is dominated by a montane food crop production system mainly located above $1800 \mathrm{~m}$ elevation. Farming plot sizes are small and fragmented due to high population density. The area has experienced a decline in soil fertility, mainly in phosphorus levels (Carswell 2002), due to repeated cultivation (Osiru 2006). 
The catchment (Fig. 1) is dominated by Lake Bunyonyi $\left(49.6 \mathrm{~km}^{2}\right)$ and discharges into River Ruhezamyenda. The mean average precipitation is $1074 \mathrm{~mm}$ (WorldClim data 19502000 mean monthly precipitation (Hijmans et al. 2005)) with heavy rains between March and May and light rains from September to November (the first dry season is from June to August and the second is from December to February).

The Ruhezamyenda catchment is hilly with steep slopes that are intensely cultivated. Elevation in the catchment ranges from 1784 to $2597 \mathrm{~m}$. The valley bottoms are often wide and flat and filled with wetlands. In many cases, these have been drained and converted to eucalyptus or to arable farmland consisting mainly of Irish potatoes, sweet potatoes, sorghum, beans and bananas (Crerar and Akurut 2017). Other crops in the catchment include field peas, maize, wheat and vegetables (Osiru 2006). Grazing land is scarce, so animals are fed on marginal hillsides, valley bottoms and fallow land (Osiru 2006). Less than half of the farmers own livestock (Crerar and Akurut 2017). Outside of the Echuya Forest Reserve, very little, if any of the original forest cover remains but there are significant areas of eucalyptus plantations.

Despite the steep slopes, terracing throughout the catchment is limited leading to high levels of erosion, especially during intense rainfall events. This results in soil (and often pebbles, cobbles and rocks) being washed from the upper slopes to the lower slopes and valley bottoms, and in extreme cases, landslides. In recent years, farmers located on the upper farmed areas of the catchment have experienced decreasing crop yields.

From 1987 to 2014, the most significant and predominant land-use change that took place in the catchment was the conversion of tropical high forests to small-scale farmland and woodlots, and the decline in the wetland areas (Kizza et al. 2017). Population pressure in the entire Ruhezamyenda catchment is responsible for these changes: the destruction of natural vegetation to meet household food and fuel needs is widespread. Hillslope areas in particular have been cleared of trees; also, swaths of wetland have been reclaimed for agricultural purposes or planted with eucalyptus trees. This has resulted in more frequent floods and landslides (Rukundo 2015).

\subsection{Hydrological modelling}

\subsubsection{Historical climate and discharge data}

Nine precipitation stations (Fig. 1) are used for the observed data from 1951 to 1977. The data has a relatively continuous time series, with 2 to 5 stations always measuring data. After using correlation analysis and linear regression to fill missing precipitation data gaps, Thiessen polygons were used to calculate areal precipitation values for the sub-basins. The mean precipitation for every sub-basin is thereby calculated as an area-weighted mean of the surrounding station time series.

Since no air temperature data was available from local weather stations, air temperature data was acquired from the Climatic Research Unit Timeseries CRU TS v.4.01 global gridded data from the University of East Anglia (Harris et al. 2014) and was used to calculate PET with the Hargreaves equation. To check the plausibility of the calculated PET, the Global PET dataset (Trabucco and Zomer 2009) was obtained which also uses the Hargreaves equation to calculate PET for Africa and is based on data from the WorldClim Global Climate Data (Hijmans et al. 2005). This is a dataset prepared as monthly averages (i.e. one layer for each month, averaged over the 1950-2000 period available from www.csi.cgiar.org). 


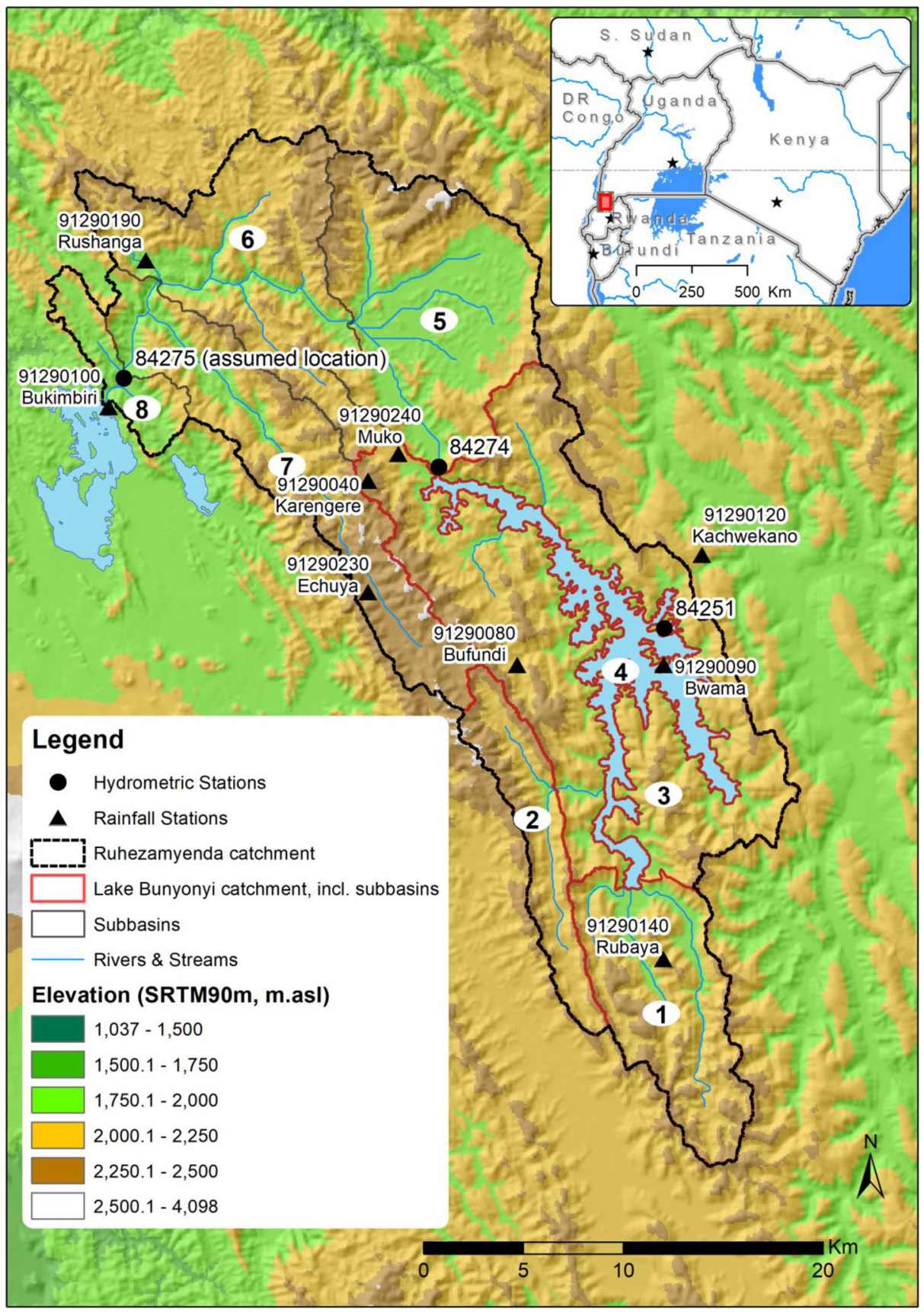

Fig. 1 Overview of the study area, topography, modelled sub-catchments 1 to 8 and hydrometric or rainfall station names with their numbers

Two hydrometric stations provide streamflow information (Fig. 1): gauge number 84274 at the Lake Bunyonyi outlet with discharge measurements from 1971 to 1995 (with substantial 
gaps in the recording) and gauge number 84251, which measured the water level of the Lake Bunyonyi at Bwama Island from 1953 to 1984 (with fewer data gaps).

An exponential relationship between the discharge and the lake water level was determined to be:

$$
Q_{W L_{\text {ExpFunct }}}=0.3213 \times W L^{4.8121}
$$

It was necessary to adjust the Lake Bunyonyi water level data due to the significant and abrupt change in water level that takes place after 1970, which may, for example, have been due to the water level gauge being shifted after an event. The difference between the mean monthly lake levels from 1953 to 1969 and 1970-1984 was calculated to be $0.54 \mathrm{~m}$. By subtracting $0.54 \mathrm{~m}$ from the lake levels recorded from the original 1953-1969 monthly lake level data, the resulting data was much more plausible.

\subsubsection{Future climate data}

The global climate simulations from the CMIP5 ensembles (Taylor et al. 2012) at a spatial resolution of $0.5^{\circ}$ were used. The required climate variables to run the hydrological model were surface precipitation amount ( $p r)$, minimum temperature (tasmin) and maximum temperature (tasmax). The period of data availability from the climate simulations was from 1950 to 2100 with two representative concentration pathways of RCP4.5 and RCP8.5. The two RCPs were chosen to capture a wide range of possible outcomes, the selections represent one of lower and one of the highest future GHG emission scenarios, respectively. Based on the CMIP5 data available, 22 climate simulations were used for the RCP4.5 future, and 30 climate simulations were used for the RCP8.5 future (Tab.Supp.1).

The climate data was acquired from the ESGF (Earth System Grid Federation; https://esgf. llnl.gov/) and downloaded and bias-corrected for the grid cell (centroid at longitude $29.75^{\circ}$ and latitude $-1.25^{\circ}$ ) relevant to this study by The Climate Data Factory (https:// theclimatedatafactory.com/). The data was bias-corrected using the CDF-t (cumulative distribution function transform) method. The observed-based reference dataset for bias adjusting the CMIP5 GCM data is the WATCH-Forcing-Data-ERA-Interim data (WFDEI: http://www.euwatch.org/data_availability). The CDF-t method for tasmin and tasmax variables uses a moving time of the large-scale CDF from the historic to the future time period (Michelangeli et al. 2009; Vrac et al. 2012). The adjusted climate simulations have the same $\mathrm{CDF}$ as the re-analysis observed-based data. The $p r$ variable was adjusted with an updated CDF-t which considers rainfall occurrence as well as intensity (Vrac et al. 2016).

\subsubsection{The hydrological model COSERO}

The hydrological simulations were performed with the conceptual rainfall-runoff model COSERO (COntinuous SEmidistributed RunOff Model; Eder et al. 2005; Stanzel et al. 2008; Kling and Nachtnebel 2009; Kling et al. 2015; Herrnegger et al. 2015, 2018). COSERO has been applied to all parts of the world (Kling et al. 2015), including several applications in the tropics and in Africa (e.g. Kling et al. 2014; Stanzel et al. 2018).

The COSERO model evolved from a model structure that was originally developed for realtime runoff forecasting (Nachtnebel et al. 1993). Since then substantial improvements have been incorporated into COSERO, e.g. for the application to water balance studies and 
distributed routing issues or for implementing new optimization methods. COSERO accounts for AET, interception storage, soil water storage, separation of runoff into flow components and routing by means of a cascade of linear and non-linear reservoirs. The main model inputs include a time series of precipitation and PET. Model outputs include simulated discharge, AET and other fluxes not analysed in this study, e.g. groundwater recharge. For a detailed description of COSERO, see Kling et al. (2015).

An advantage of COSERO is the flexibility of its application, depending on the availability of data. Given the limited availability of spatially distributed data in the Ruhezamyenda catchment, i.e. for soil texture and meteorological inputs, the model was set up in a lumped manner, whereby relevant soil parameters are estimated in the calibration step.

For the application of the COSERO model to the Ruhezamyenda catchment, the catchment was divided into eight sub-basins (Fig. 1) based on the hydrometirc station locations and on the confluences of main rivers. The physical Lake Bunyonyi is located in sub-basin 4, while sub-basins 1 to 4 belong the catchment of Lake Bunyonyi. Continuous simulations (monthly time step) were performed from 1951 to 2100 . The period 1951-2000 was used for model calibration (see Supp.Mat.2 for calibration details), and the periods 2041-2070 and 2071-2100 for assessing the mid-term and far future developments, respectively, of the water components.

\subsection{Stakeholder workshop on adaptation strategies}

From the results of the hydrological assessment with the COSERO model, a few possible climate change adaptation options were pre-identified by the authors. These adaptations however needed to be expanded on as well as validated with resident stakeholders. Participatory processes have been used successfully in hydrological modelling studies in connection with climate vulnerability assessments to identify local potential adaptation strategies in Africa (Andersson et al. 2013; Bornemann et al. 2019) and are particularly informative for integrating scientific knowledge in water resources management because they provide informative, inclusive and transparent decision-making while enhancing the quality of decision implementation (Giupponi 2014), e.g. for adaptation.

To this end, a participatory workshop was held in Kabala on November 22, 2018. The workshop was co-organized by the GoU (Ministry of Water and Environment) and IISD (see Supp.Mat.3 for workshop program). The participants were selected and subsequently invited by both organizations based on their involvement in water management in the Lake Bunyonyi and Ruhezamyenda catchments. Their participation purposes were to learn about the potential climate change impacts, to validate the adaptation strategies proposed and to contribute toward identifying knowledge gaps and/or further adaptation strategies.

In total, 32 participants took part in various organizations (Tab.Supp.3). During the workshop, after a short introduction to modelling, the results of the hydrological assessment and the preliminary adaptations were presented. For the breakout session, the stakeholders were divided into thematic groups of interest. Each group was asked to consider the results of the modelling assessment and the proposed adaptation options. They were provided with the following questions to guide their discussion:

1. Is the list of issues presented complete?

2. What are the current climate vulnerabilities facing your group?

3. Are there any impacts which will play a major or dominant role in your group? 
4. How has your group dealt with extreme or variable climate/weather events in the past?

5. What does your group need to know to facilitate adaptation to climate change?

The information from each group was summarized and presented to all participants for feedback and discussion. A final synthesis of the results was undertaken after the workshop.

\section{Results}

\subsection{COSERO model calibration for the Ruhezamyenda catchment}

The COSERO model was calibrated at a monthly time step for the period from 1951 to 2000 (with a warmup period from 1951 to 1958).

The COSERO model performed quite well for the historic period since the observed dynamics, and magnitudes of annual runoff are captured well by the COSERO simulation (Supp.Mat.2).

\subsection{Future climate simulations for the Ruhezamyenda catchment}

\subsubsection{Changes in temperature}

In Fig. 2 the mean monthly temperature graphs show the red line represents the CRU TS v4.01 data, and the blue areas represent the temperature from the GCMs. Here (and in the other plots), the different shadings of blue indicate the quantiles of the GCM ensemble.

Based on the median of all GCMs and for both RCPs, the mean monthly air temperature in the Ruhezamyenda catchment is simulated to increase by approximately $1.5-3.0{ }^{\circ} \mathrm{C}$ in the mid-term future $2041-2070$ and by roughly $2.0-4.5^{\circ} \mathrm{C}$ in the far future $2071-2100$. For all of the GCM simulations, the air temperature shows rather uniform increases in all months and in all future scenarios. The increase in temperature rises continuously with time. The temperature increases as indicated by the median of the GCMs in RCP8.5 for the period 2041-2071 is $2.5^{\circ} \mathrm{C}$ higher in August, and it increases even more in the RCP8.5 scenario, in which the median of the GCMs is $4.5^{\circ} \mathrm{C}$ higher in August for the period 2071-2100. Although all models agree that temperature will increase, the range of uncertainty for the increases remains large.

The future shows a general increase in temperature in all GCMs. This is not only the case for the median, but for all single GCM ensemble members. However, a large spread in the results is also evident. The dry season remains the cooler season, but by 2071-2100 in the RCP8.5 scenario, the mean monthly temperature remains almost as high as during the wet seasons.

\subsubsection{Changes in precipitation}

Overall, the precipitation in the Ruhezamyenda catchment is shown to increase in most years (Fig. 3). Depending on the RCP scenario and the future period considered, increases of about $150 \mathrm{~mm} /$ year (RCP4.5) to $275 \mathrm{~mm} /$ year are simulated, compared to 1971-2000. Higher uncertainty in the increases in precipitation by 2071-2100 in the RCP8.5, especially during the rainy seasons is shown (i.e. from April to May), signifying that the GCM models do not 

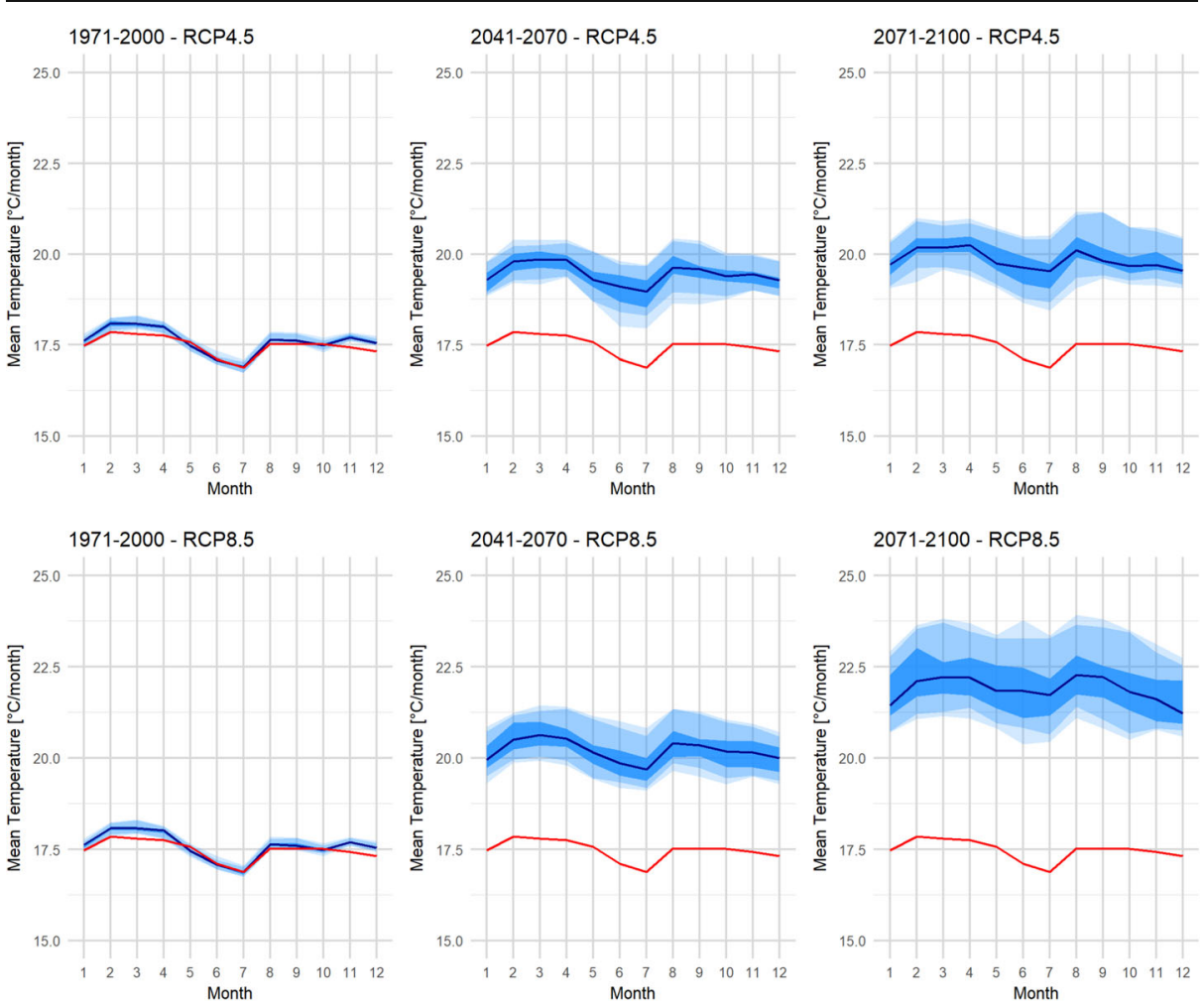

$$
\begin{gathered}
\text { Quantiles (GCMs): } \square \text { (a) } 5-95 \% \square \text { (b) } 10-90 \% \square \text { (c) } 33.3-66.7 \% \\
\quad-1971-2000 \text { (Station data/CRU) - Median (GCMs) }
\end{gathered}
$$

Fig. 2 Mean monthly temperature $\left[{ }^{\circ} \mathrm{C}\right]$ for the periods 1971-2000 (left), 2041-2070 (middle) and 2071-2100 (right) (top: RCP4.5; bottom: RCP8.5) for the Ruhezamyenda catchment

agree. The reason for the large peak during this time was due to one of the GCMs simulating rather large events during these months. Since all climate simulations are plausible future outcomes, this indicates that more uncertainty may be expected in precipitation received during the spring months.

The precipitation in the wet months is simulated to increase more than for the dry months in all future scenarios. Compared to 1971-2000, the mean annual precipitation is generally simulated to increase for the mid-term future and for the far future. For the future, the RCP4.5 scenario has simulated increases between approximately 0 to $50 \%$ and for RCP8.5 simulated changes lie between -25 and $+75 \%$.

\subsubsection{Actual evapotranspiration}

The AET was simulated with COSERO and mostly relies on the availability of water and on the PET, but it is also determined by vegetation cover and land use. The increase in air temperature will lead to overall higher AET in the Lake Bunyonyi catchment.

In Fig. 4, the changes in AET show -100 to $+220 \mathrm{~mm} /$ year (RCP4.5) and -200 to + $300 \mathrm{~mm} /$ year (RCP8.5). The median of the GCM simulations increased in all months for the 

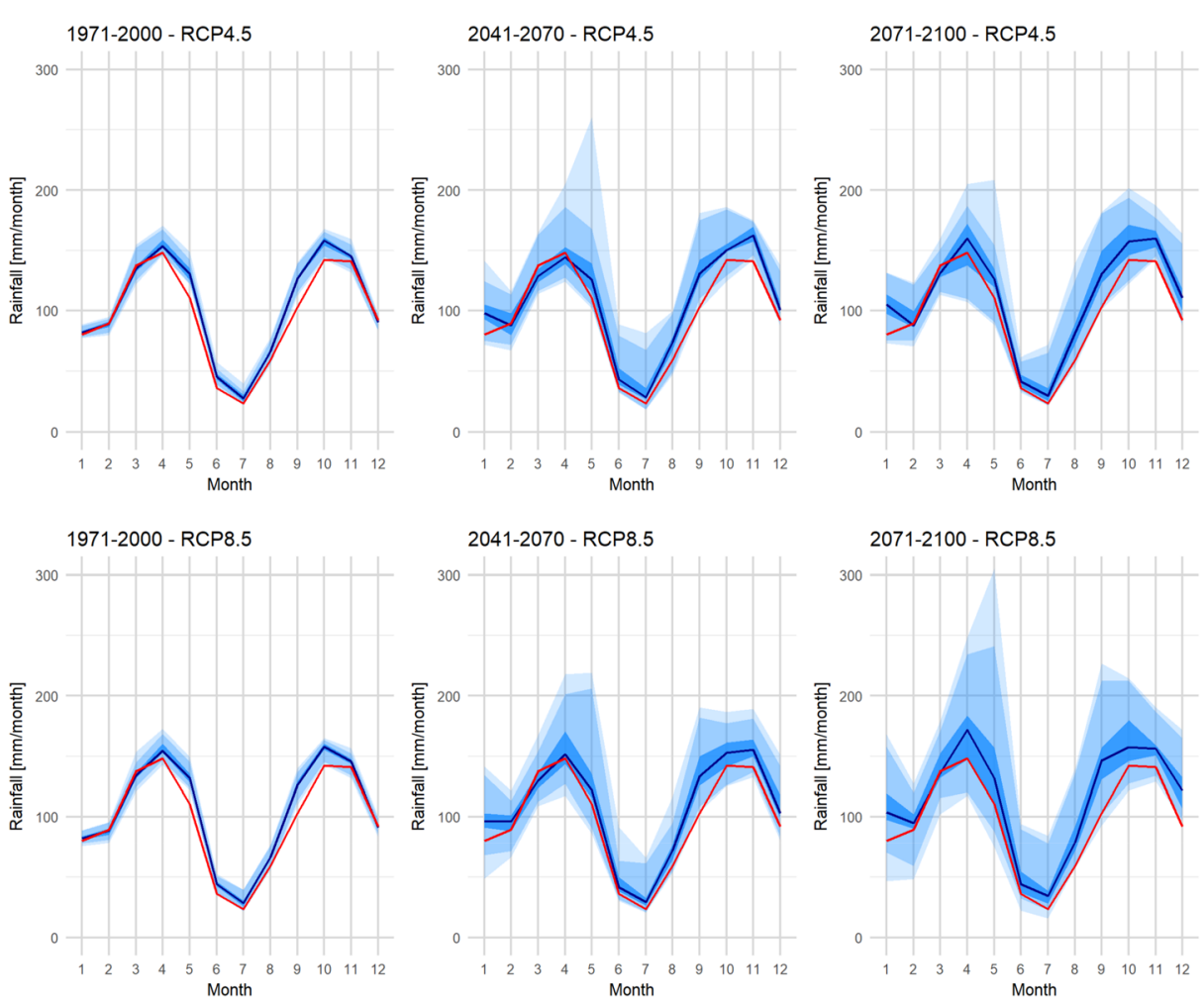

Quantiles (GCMs): $\square$ (a) $5-95 \%$ (b) $10-90 \% \square$ (c) $33.3-66.7 \%$

\section{- 1971-2000 (Station data/CRU) - Median (GCMs)}

Fig. 3 Mean monthly rainfall [mm/month] for the periods 1971-2000 (left), 2041-2070 (middle) and 20712100 (right) (top: RCP4.5; bottom: RCP8.5) for the Ruhezamyenda catchment

future periods, with an increase of approximately $8 \mathrm{~mm} / \mathrm{month}$ in the median of all GCMs in the RCP8.5 scenario for the far future, although with notable uncertainty concerning the magnitudes. The AET increased the most during the months of May to August in all scenarios. It is worth noting that for the RCP8.5 scenario, the months of January and February show the largest uncertainties (due to the direction of change that is not consistent).

\subsubsection{Changes in runoff}

For the period 1971-2000, the annual runoff in the Lake Bunyonyi catchment simulated using observed values (in situ stations and CRU TS data) is in the range of the GCM data (Fig. 5); however, a larger spread in the GCM results is evident. For 2041-2070, the median of the GCMs shows a similar seasonality compared to the reference period. There is an indication that the runoff at the beginning of the year increases slightly. For 2070-2100, most GCMs simulate an increase in runoff for all months of the year. For both future periods, it is also evident that the GCMs do not fully agree, since the spread in the results is very large.

The runoff simulated at the outlet of Lake Bunyonyi for the future periods 2041-2070 and 2071-2100 shows that there is no overall trend toward only an increase in runoff. In all 

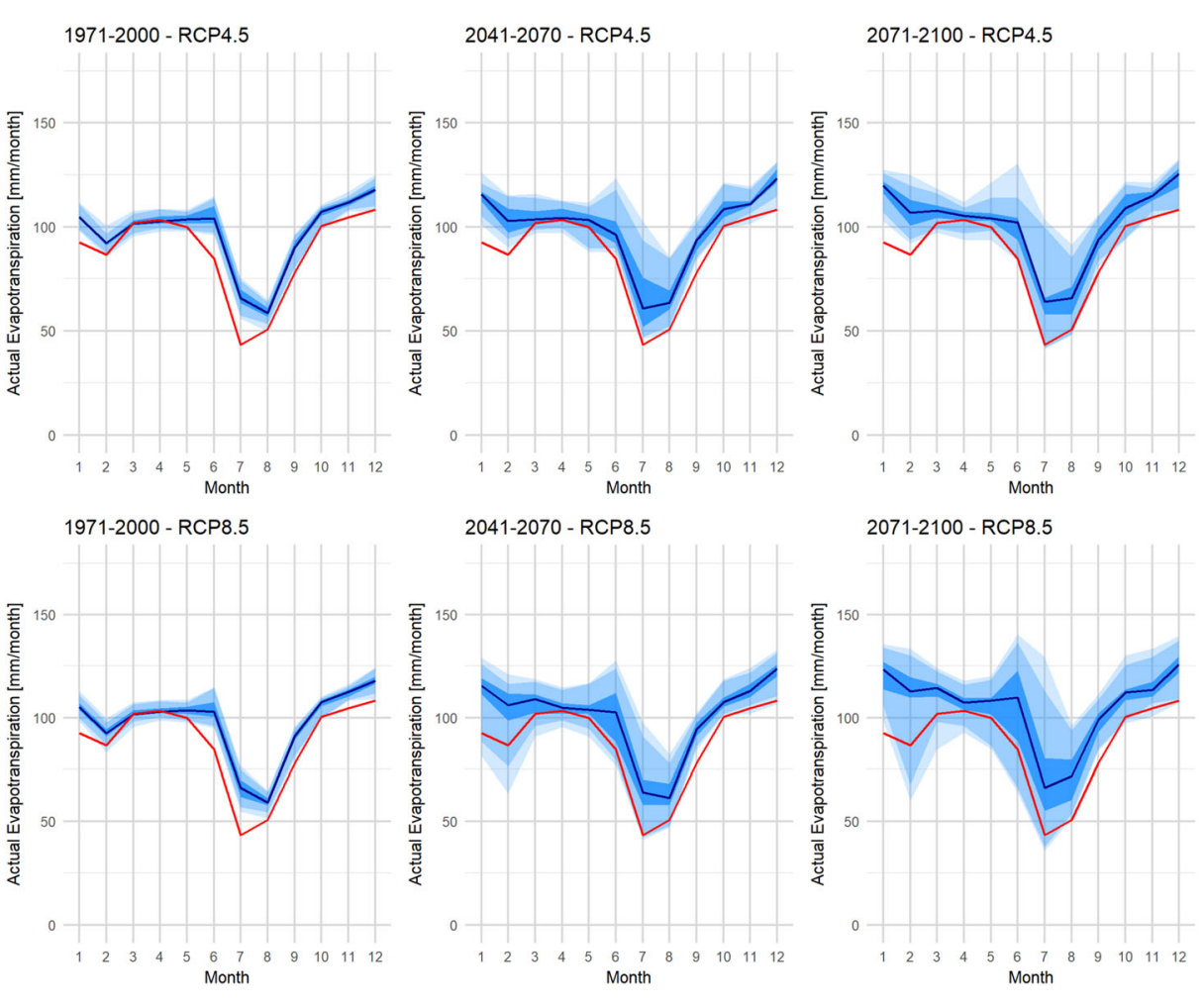

Quantiles (GCMs):

(a) $5-95 \%$

(b) $10-90 \%$

(c) $33.3-66.7 \%$

- 1971-2000 (Station data/CRU) - Median (GCMs)

Fig. 4 Mean monthly actual evapotranspiration $[\mathrm{mm} / \mathrm{month}]$ in the Lake Bunyonyi catchment for the periods 1971-2000 (left), 2041-2070 (middle) and 2071-2100 (right) (top: RCP4.5; bottom: RCP8.5)

months, lower runoff and higher runoff are simulated, once again highlighting the uncertainties in the GCM simulations. The simulations show that due to the overall monthly increases in precipitation and temperature, and despite the simulated increases in monthly PET and AET, the runoff in the Lake Bunyonyi will be altered; lower runoff amounts in some months, but overall higher runoff amounts are simulated, particularly in the far future (2071-2100) in the RCP8.5 scenario. Much uncertainty remains in the direction of mean monthly runoff changes, especially for the mid-term future (2041-2070).

\subsection{Uncertainties in the modelling results}

As in all modelling exercises, these results contain a number of inherent uncertainties. For example, by applying climate simulations in a hydrological model, the uncertainties are cascaded through the modelling chain and are related to the natural climate variability; the greenhouse gas emission (RCP) scenario; the GCM structure; the choice of the hydrological model, the data input, as well as the calibration process (Wilby 2005).

Hawkins and Sutton (2011) showed that the choice of GCM contributes 80-90\% of the projected precipitation uncertainty during the rainy seasons (MAM and SON) in Africa for the future periods analysed in this study. This high uncertainty poses a challenge when 

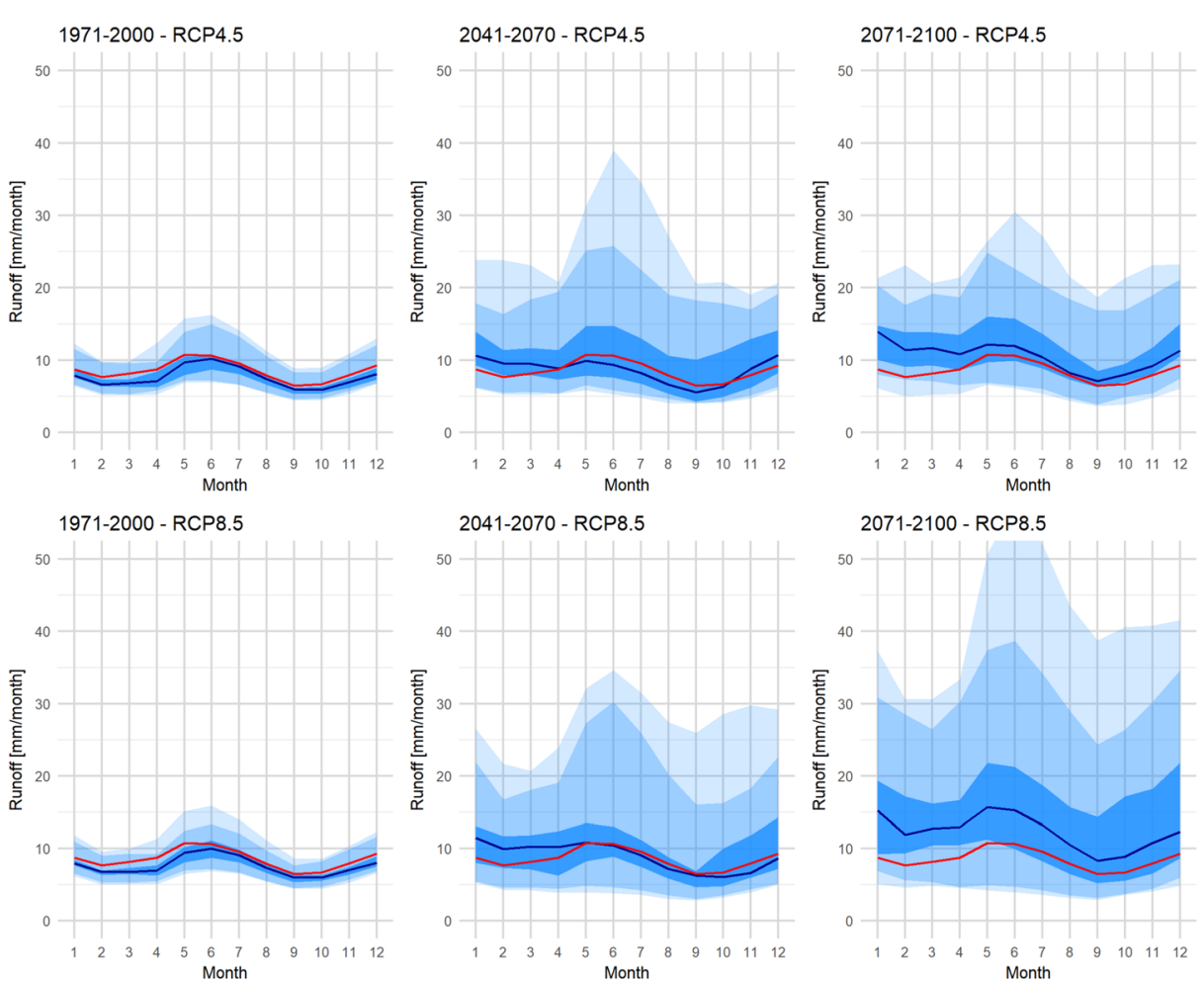

Quantiles (GCMs):

(a) $5-95 \%$

(b) $10-90 \%$

(c) $33.3-66.7 \%$

- 1971-2000 (Station data/CRU) - Median (GCMs)

Fig. 5 Mean monthly runoff $[\mathrm{mm} / \mathrm{month}]$ in the Lake Bunyonyi catchment for the periods 1971-2000 (left), 2041-2070 (middle) and 2071-2100 (right) (top: RCP4.5; bottom: RCP8.5)

making long-term decisions for water resources planning (Bornemann et al. 2019). To deal with these uncertainties, we use a suite of climate change models, each with two emission scenarios, to capture a large extent of the uncertainty in the climate projections. Furthermore, we ensure the hydrological model can reproduce the historic water balance conditions in the catchment before the climate simulations are applied.

The COSERO hydrological model was set up as a spatially aggregated model for each sub-basin and achieved good calibration results for the historic period, especially considering the general challenge of dealing with missing in situ observation data. For example, the missing precipitation data was estimated using a correlation analysis with other station data in the catchment. And where no station data was available, time series from the CRU TS v4.01 gridded dataset was used. The hydrological model also did not take into account detailed soil maps, land uses or water abstractions (Supp.Mat.2). Despite the uncertainties, we are highly confident that the model simulations of the past show plausible results.

Communicating and dealing with uncertainty in the model results, especially for decisionmaking, is daunting (Kiem et al. 2016). In the workshop, this was partly dealt with by presenting the medium of the modelled hydrological outcomes and assigning quantile percentages (according to model agreement) to the range of changes simulated. 
Despite the uncertainty in the future simulations, the current models are the best tools we have to provide water managers and stakeholders knowledge of the potential impacts (trends, direction and relative amounts) on precipitation, runoff and evapotranspiration changes in the Ruhezamyenda catchment to subsequently operationalize adaptation (Wilby and Dessai 2010).

\subsection{Adaptation options for the catchment}

Based on the simulated results, the authors identified that the Ruhezamyenda catchment can particularly benefit from no-regrets (or low-regrets) adaptation options. No-regrets adaptation options are beneficial to several sectors and consider impacts beyond climate change alone. They aim to provide prudent climate risk management considering a range of possible impacts on multiple sectors. Several no-regrets adaptation actions have already been identified in the existing Ruhezamyenda CMP report (Rukundo 2015) and remain relevant based on these results.

The 1-day workshop held with stakeholders working in water resources management in the catchment was successful in its goals to validate the no-regrets adaptations pre-identified by the authors, as well as to propose further adaptation strategies. Participants whose livelihoods depend on the climat impacts, deliberated over the results of the qualitative modelling assessment in thematic groups and through a cooperative, bottom-up process they considered the hydrological changes that may take place in the future. The outcome was a targetted contribution of knowledge and a myriad of expertise to develop a broader range of specific adaptation recommendations that were locally accepted as water management options.

The possible climate change adaptation strategies established together by the authors and the stakeholders can be divided into five themes: governance; capacity development and communication; water, soil, land management and livelihoods improvement; data management; and research. A summary of the findings is presented in Table 1. The following sections (3.4.1-3.4.5) present and discuss each of the five themes in turn, whereby the adaptation options are listed as subheadings in italics.

\subsubsection{Governance}

Accelerate and scale up the implementation of adaptation measures identified in the CMP (Rukundo 2015), some of which have already been successfully piloted in the catchment. Several pilot projects focusing on water, soil and land conservation are underway to support climate change adaptation while also improving peoples' livelihoods. The participants highlighted that they have dealt with extreme weather events in the past through implementing various soil and water conservation measures, including water harvesting technologies, implementing agroforestry, planting early maturing crop varieties, integrating chicken in crop production systems and diversifying enterprises. As such, relevant adaptation actions are already being implemented in the catchment demonstrating that local stakeholders are proactive and eager to adapt to climate change if it can also improve their livelihoods. The approach of establishing pilot demonstration sites in partnership with some farmers - and sharing these experiences with neighbours - was deemed as useful, but the process needs to be accelerated and scaled up to have a real impact. It was stressed that too little is being done on the ground, leading to the continuous deterioration of the environmental and socioeconomic situation.

Prioritize access to climate finance to implement adaptation priorities in the catchment. The change required for adaptation to occur in the catchment is slow to take place in the community and necessitates appropriate and continuous financial resources. 
Table 1 Summary of climate change adaptation options for the Ruhezamyenda catchment

Thematic area $\quad$ Adaptation action and perceived barriers to adapt $\begin{aligned} & \text { Climate impact(s) being } \\ & \text { targeted }\end{aligned}$

Governance

Communication and capacity development

Water, soil, land management and livelihoods improvement

Data management

Research
Accelerate and scale up the implementation of adaptation measures identified in the catchment management plan (CMP)

Barrier is logistical, i.e. not implementing measures fast enough

Prioritize access to climate finance to implement adaptation priorities in the catchment

Barrier includes the perception of a lack of climate change urgency

Engage with women and men in the communities and local stakeholders to introduce improved farming practices

Barriers include lack of resources (financial, personnel)

Develop, communicate and enforce bylaws to protect the catchment

Barriers include lack of resources and enforcement

Enhance coordination and collaboration across sectors and levels of governance to support alignment between the CMP and other sectoral and local development plans and their effective implementation

Barriers include the challenge of collaboration between several actors from the national to the local level and poor cross-sectoral communication

Develop and implement a communication strategy on climate change impacts and adaptation in the catchment

Barrier is providing adequate training and resources

Train farmers and other actors on no-regrets adaptation options

Barrier includes convincing farmers of the benefits

Manage excess surface runoff in the catchment to reduce soil erosion and infrastructure damage

Barriers include lack of resources and coordination

Implement and maintain terraces and bund systems

Barriers include lack of resources for maintenance

Conserve the wetland areas in the catchment

Barriers include the increasing population pressure, lack of suitable alternative agriculture land and poor enforcement of the current bylaws

Instal and maintain hydrometric and meteorological stations throughout the catchment

Barriers include logistical challenges, lack of resources and no plan to make data available

Monitor sub-daily precipitation

Barriers include logistical challenges and lack of resources

Establish and implement protocols for climate data management

Barrier includes poor communication between relevant sectors

Undertake local assessments of climate change impacts in vulnerable areas of the catchment

Barriers include lack of resources

Determine the drivers of land-use change in the catchment

Barriers include lack of resources
Extreme events, i.e. rainfall and/or drought

All

Soil erosion, excess water, lack of water, decreased yields

Flooding, drought, soil erosion

Soil erosion, infrastructure damage

Soil erosion, decreased crop yields, draining wetlands,

Flooding, surface runoff, fluctuating lake levels, sedimentation

Planning adaptation options

Extreme rainfall events, soil erosion

planning adaptation options

Surface runoff, lack of water, soil erosion,

Actual evapotranspiration, surface runoff, soil erosion 
Engage with women and men in the communities and local stakeholders to introduce improved farming practices. As identified in the CMP (Rukundo 2015) under "Objective 1: To promote sustainable land management practices for co-existence of human land use and environmental sustainability in Ruhezamyenda Catchment", actions include to stimulate the formulation of functional institutional frameworks through generally acceptable and universally respected platforms with active involvement of stakeholders and local council leaders to promote sustainable land management practices and integrate available Indigenous knowledge of women and men into the new farming methods for faster adoptability.

Develop, communicate and enforce bylaws to protect the catchment. To implement adaptation actions successfully, bylaws need to be developed and communicated to the stakeholders to increase their awareness and so that the most vulnerable areas are protected. For example, encroaching on wetlands currently has no legal consequence in the Lake Bunyonyi catchment. The communities living around Lake Bunyonyi require specific bylaws to prevent the draining of wetland areas for planting agricultural crops and eucalyptus woodlots. These bylaws should be developed and enforced by the local population.

Enhance coordination and collaboration across sectors and levels of governance to support alignment between the CMP and other sectoral and local development plans and their effective implementation. Ensuring that the adaptation actions identified in the CMP are reflected in other sectoral and district development plans could support their effective implementation. The assessment of climate change impacts and the implementation of adaptation measures requires the collaboration of many actors from the national to the local level. This is a major challenge to implementing the Ruhezamyenda CMP, as well as other CMPs in Uganda. Specifically, there seems to be a governance challenge or mismatch in terms of the scale of implementation, i.e. water management zones are not matching administrative units (district, parish), and the thematic structure, i.e. how to implement water catchment management plans that are cross-sectoral when the government is still organized into sectors? The workshop participants indicated that the sectors are not working well together, which is perceived as a barrier to implementing adaptation measures.

\subsubsection{Communication and capacity development}

Develop and implement a communication strategy on climate change impacts and adaptation in the catchment. Existing reports need to be communicated appropriately to the end users. A communication strategy targeting the different stakeholders of the catchment is urgently needed. Communicating climate change impacts to various stakeholders and decisionmakers is a challenging task. Climate simulations often have a large range of uncertainty associated with them. Ideally, this adaptation needs to be supported with capacity building for the scientific community on the use and application of hydrological models and on the use of climate model outputs to improve the communication - and therefore the impacts - of the study results.

A communication strategy could contribute to the following three areas: (i) preparedness for the changes by promoting regular updates to the communities on the current and future impacts of climate change, (ii) improved effectiveness of adaptation responses by collecting regular communities' feedback on adaptation priorities and barriers and enablers to adaptation, and (iii) accelerate the effective implementation of adaptation actions by promoting dialogues on climate adaptation (what is working well, or not, in specific contexts and for whom) among 
communities but also between international and local scientists and between scientists and decision-makers.

Existing institutional arrangements, such as the disaster management committees, were identified to potentially sensitize communities on these issues, if they are provided with adequate training and resources.

Train farmers and other actors on no-regrets adaptation options. All the proposed measures will be very difficult to introduce and implement effectively unless stakeholders can see the benefits. Discussions with local stakeholders highlighted that adaptation to climate change alone is not a priority for people living in the catchment. Adaptation measures will only be successful if they also improve the livelihoods of the smallholder farmers, the fishermen and other local entrepreneurs who are mainly concerned with feeding their families. All the priority adaptation actions identified need to be combined with customized communication and training programmes to support community engagement.

\subsubsection{Water, soil and land management and livelihoods improvement}

Manage excess surface runoff in the catchment to reduce soil erosion and infrastructure damage. The workshop participants identified the need to manage excess surface runoff after rainfall events. From past experiences, they perceive that heavy rainfalls exacerbate surface runoff. Measures identified for surface water runoff collection and management include the following: collecting water from roofs and using the water for irrigation needs during the dry periods; insuring that road construction plans include surface water runoff control to redirect the water from the roads away from the fields; engaging communities in a coordinated approach to implement other soil and water conservation structures such as constructing trenches and terraces.

Implement and maintain terraces and bund systems to improve crop yields and manage soil erosion in the catchment. Terraces and bund systems can contribute to attenuating rainfall erosivity, reducing soil erosion and encouraging infiltration instead of surface runoff. Improving the productivity and therefore livelihoods of farmers on the hillside will reduce pressure on the wetlands. Up to the 1960s, farmers managed the steep agricultural land well with the use of terraces or stone bunds, but these have not been maintained over the years. The CMP identifies several structural measures that are relevant, e.g. "Objective 2: To restore the catchment health and address priority water-related risks and disasters". Given the steep hills that are used for farming and for planting eucalyptus, the upkeep of the terraces or bund systems to manage soil erosion is a very important measure to attenuate soil loss during heavy rainfall events.

Conserve the wetland areas in the catchment. The conversion of wetlands to farmland or to eucalyptus woodlots in the catchment threatens to change the hydrology of the basin and should be halted, and the wetlands restored. A large proportion of the lowland wetland systems has been converted into productive agricultural land, and this conversion continues. The population pressure, coupled with the reduced productivity levels of the uplands due to soil erosion, may increase the pressure on farmers to move into wetland areas. The CMP (Rukundo 2015) under objective 2 also identifies measures for wetland conservation. Wetlands play an important hydrological role to store water and are a valuable natural barrier for attenuating lake level fluctuations, small floods and sedimentation caused by heavy rains. This measure should be associated with complementary measures such as: encouraging alternative sources of fuelwood, which would help free up land for agriculture instead of for biomass; providing training for sustainable land management practices to rehabilitate the degraded wetlands, 
which would restore already degraded wetlands; and implementing awareness campaigns to promote the benefits of wetlands and further prevent wetland drainage.

\subsubsection{Data management}

Instal and maintain hydrometric and meteorological stations throughout the catchment, but especially at the outlet of Lake Bunyonyi and the outlet of the Ruhezamyenda catchment, to monitor the precipitation and particularly the discharge and the lake levels in the catchment. Recorded historic data is the foundation of observing changes in the catchment and assessing potential impacts caused by climate or other geophysical events, including for calibrating models. Several critical points concerning the quality of the input data for the simulation of the historic conditions from 1971 to 2000 arose during the study (see Section 2.2). As such, the establishment and strengthening of a continuous system to monitor the bio-physical conditions in the catchment are necessary so that the current situation can be assessed and changes monitored.

The workshop participants stated that local institutes and governments have been equipped with automated weather stations to collect and store data. This data needs to be made available for research and it needs to be quality controlled. Maintaining a hydro-meteorological observation network is a complex task. Further satellite-based, hydrologically relevant, data series have recently become available, but this development does not eliminate the necessity of in situ field observations. Instrumented on-site measurements are essential to observe and monitor ongoing changes in the hydrological cycle to make objective, data-based decisions for the management of water resources or to assess potential changes in the hydrological components in the future. A good example in this context is the long-term observations of the Nile at Jinja or the Lake Victoria water levels (Sutcliffe and Parks 1999; Sutcliffe and Petersen 2007).

Monitor sub-daily precipitation events at 15- or 30-min intervals particularly in a variety of landscapes found in the catchment, such as steep hills and lowlands. This data is highly useful to estimate erosion rates due to intense precipitation events. According to the CMP (Rukundo 2015), soil erosion is one of the main challenges in the catchment. Calculating soil erosion can be undertaken with the empirical Universal Soil Loss Equation, which uses several factors to estimate annual soil erosion. One of the factors is the rainfall erosivity that represents the total storm kinetic energy per unit area and is a product of the precipitation intensity. The lack of rainfall data for short-term intense events is a major challenge to understanding the soil erosion processes in the catchment. With sub-daily precipitation data, statistical analysis can also be applied to determine the number of extreme rainfall events in the recorded time period and make inferences about any extreme precipitation changes in the catchment.

Establish and implement protocols for climate data management. This is especially important to strengthen the exchange of data between the Uganda National Meteorological Authority (UNMA) and the Ministry of Water and Environment. Obtaining climate data from UNMA is, in theory, possible, and a memorandum of understanding (MoU) between some institutes exists, but if the application for data is successful, the data exchange can take months.

\subsubsection{Research}

Undertake site-specific assessments of climate change impacts in vulnerable areas of the catchment. Many workshop participants stressed the importance of carrying out local 
interventions of soil management at the sub-catchment or at the community level. This study focuses on the impacts of climate change on the Lake Bunyonyi catchment, and the next step needs to address local, site-specific assessments of climate change impacts to assess, for example, the quantity of runoff in specific vulnerable areas in the catchment that consider a diversity of physical terrains, water availability, infrastructure and other factors.

Determine the drivers of land-use change in the catchment to understand how land use/ land cover will evolve in the future, especially due to the growing population. This will enable future hotspots of change to be identified (also related to potential soil erosion) and allow appropriate incentives and policies to be put in place to promote sustainable land management practices, and also to improve the implementation of soil and water conservation measures.

According to Osiru (2006), the main driver for widespread degradation of the land is the population density, which has pushed farming to marginal areas (i.e. on steep slopes). In the CMP, it is stated that "human induced land-use change has adversely affected the hydrological conditions of the area with local stakeholders reporting regular drying of streams and small wetlands during dry seasons" (Rukundo 2015). Subsequently, the local characterization of soils should be undertaken, as the soil type strongly influences the hydrological processes that occur. Given that two thirds of the basin are already farmed for food and fuel, the changes in the land use must be examined as a future task. Future changes in land use, especially the farming of steep hillside slopes, may impact the catchment hydrology and be a driver for soil erosion and water quality changes. Furthermore, the combined effects of land use and climate change can impact the hydrological components of infiltration, evapotranspiration and surface runoff in particular.

\section{Discussion}

The overall trends from the hydrological components simulated for the Lake Bunyonyi catchment show the risk for significant shortcomings in water availability for the future 2041-2070 and 20712100 to be low. An exception may be if the future implementation of large-scale irrigation schemes or dam construction projects takes place or other (e.g. domestic) water demands increase significantly. Almost $65 \%$ of the Lake Bunyonyi catchment is farmland and therefore heavily influenced by human activities. For Uganda, subsistence agricultural land use is projected to continue to be the dominant change in the future ( $\mathrm{Li}$ et al. 2016; Majaliwa et al. 2018), and thus, the problems with landslides and erosion will likely continue. Local changes in land use/land cover need to be assessed for impacts on runoff, infiltration or soil water storage. If the wetland areas continue to be drained, it may affect the lake levels.

The variability in the historic Lake Bunyonyi water levels and discharge is confirmed by other studies conducted in the region. Although the regional climate can show local variability, inter-annual fluctuations are markedly uniform in eastern Africa and appear to be governed by factors linked to large-scale atmospheric and oceanic factors. Rainfall fluctuations show strong links to the El Nino-Southern Oscillation (ENSO), with rainfall tending to be above average during ENSO years. The main causal mechanisms appear to be fluctuations in sea surface temperatures in the tropical Atlantic and Indian Oceans, which in turn are loosely coupled to the ENSO (Nicholson 1996). The hydro-meteorological observations for Lake Victoria show significant variability in water levels and discharge. For the period 1901-1960, the mean annual outflow from Lake Victoria was about $20 \mathrm{~km}^{3} \mathrm{yr}^{-1}$, with small variations $( \pm 10 \%)$ in the decadal means. In contrast, in the period 1961-1970, the discharge doubled to $>40 \mathrm{~km}^{3}$. 
Similarly, Lake Tanganyika shows large increases during this period (Grove 1996). Since 1970, the flows have declined but are still high compared to the first half of the last century (Sutcliffe and Parks 1999; Sutcliffe and Petersen 2007).

Overall, the climate risks facing the catchment in the future are broad. They include dealing with too much water (higher precipitation amounts in general) and more variability in precipitation (for RCP8.5, the future periods 2041-2070 and 2071-2100 had mean standard deviations in mean monthly precipitation amounts of $56 \mathrm{~mm} / \mathrm{month}$ and $65 \mathrm{~mm} / \mathrm{month}$, respectively, compared to the historic period 1971-2000, which had a mean standard deviation of $44 \mathrm{~mm} / \mathrm{month}$ ). The uncertainties in the discharge cannot exclude more low-flow periods occurring as well or changes to groundwater levels (not examined in this study). Furthermore, while total annual precipitation may increase, we did not examine the intensity of the rainfall events nor the occurrence of dry spells, which require precipitation data at a higher temporal resolution than used in this study.

The climate change signal for temperature is stronger than for precipitation, which is confirmed by the literature (e.g. Hawkins and Sutton 2011), this uncertainty in future precipitation encumbers implementing adaptation, particularly when an investment is required. Thus, we focused on noregret adaptations that could be implemented immediately and that would also improve livelihoods in the short term. For example, measures to conserve soil water and reduce ET have been proposed as suitable adaptations for Uganda (Kikoyo and Norbert 2016). Several such adaptations were validated by workshop partcipiants, who also emphasized the need for action now. The input of the participants greatly enhanced the development of targeted and relevant adaptation options to improve livlihoods The main barriers identified in implementing adaptation were related to awareness raising, mobilizing resources and capacity building.

\section{Conclusion}

Given the selected scenarios and the hydrological modelling tool, we evaluated the future trends and the magnitude of hydrological changes in the Ruhezamyenda catchment, with a focus on Lake Bunyonyi. For the periods 2041-2070 as well as 2071-2100, and subsequently, through a participatory workshop, the results were presented to stakeholders who helped to inform local adaptation measures for the catchment.

Precipitation in the Ruhezamyenda catchment will increase in most years, but the uncertainty in precipitation amounts is high especially for the far future 2071-2100. The actual evapotranspiration in the Lake Bunyonyi catchment is simulated to increase in all months, with the median of the GCM simulations increasing the most during the months from May to August. For the future periods 2041-2070 and 2070-2100, there is a slight trend toward increasing runoff from the Lake Bunyonyi catchment compared to the period 1971-2000, but with large uncertainties. The overall trends for these hydrological components simulated for the Lake Bunyonyi catchment show that the risk for significant shortcomings in water availability for the future is low. Climate change impacts will therefore revolve around dealing with excess water and the consequences of this, such as soil erosion abatement. However, the model simulations do not preclude periods of water shortages and drought that may occur, particularly at the intra-annual scale.

The Ruhezamyenda catchment is currently experiencing many challenges such as soil erosion, landslides, floods, soil fertility loss, deforestation and wetland degradation. The results of the study highlight that excess surface runoff and all of its consequences will remain a critical impact, 
which along with the other impacts requires planned management. The first step toward adaptation, as identified by the stakeholders, is to focus on the most vulnerable areas. This includes undertaking site-specific assessments of climate change impacts on runoff in a diversity of terrains, soils, water availability and infrastructure conditions in the catchment to enable future hotspots of potential erosion to be identified and allow appropriate measures to be developed.

Overall, for the Lake Bunyonyi catchment, a combination of different types of adaptation actions is needed at the local scale - beyond structural or technical adaptation actions solely. Concrete adaptation measures in the areas of governance; capacity development and communication; water, soil and land management and livelihoods improvement; data management; and research were identified. The breadth of adaptation strategies highlights the intricacies in the Ruhezamyenda catchment and underscores the need for coordinated action between the sectors to implement adaptation in partnership.

The hydrological modelling exercise was undertaken to determine the vulnerability of hydrological components in the Ruhezamyenda catchment. During a workshop, stakeholder input was sought on adaptation actions. The stakeholder engagement was useful to (a) communicate the potential impacts of climate change to local groups, (b) obtain feedback and validation on adaptation strategies and (c) help to ensure that long-term decisions are robust to a range of possible futures. Although the adaptation measures were developed for the specific case study catchment, the development process can be used as a blueprint for other tropical catchments.

Supplementary Information The online version contains supplementary material available at https://doi.org/ 10.1007/s10584-021-02958-9.

Funding Open Access funding provided by University of Natural Resources and Life Sciences Vienna (BOKU). Funding for the research was provided by Austria through the NAP Global Network, the secretariat of which is hosted by the International Institute for Sustainable Development (IISD).

\section{Compliance with ethical standards}

Conflict of interest The authors declare that they have no conflict of interest.

Open Access This article is licensed under a Creative Commons Attribution 4.0 International License, which permits use, sharing, adaptation, distribution and reproduction in any medium or format, as long as you give appropriate credit to the original author(s) and the source, provide a link to the Creative Commons licence, and indicate if changes were made. The images or other third party material in this article are included in the article's Creative Commons licence, unless indicated otherwise in a credit line to the material. If material is not included in the article's Creative Commons licence and your intended use is not permitted by statutory regulation or exceeds the permitted use, you will need to obtain permission directly from the copyright holder. To view a copy of this licence, visit http://creativecommons.org/licenses/by/4.0/.

\section{References}

Adhikari U, Nejadhashemi AP, Herman MR (2016) A review of climate change impacts on water resources in East Africa. Trans ASABE. https://doi.org/10.13031/trans.58.10907

Andersson L, Wilk J, Graham LP, Warburton M (2013) Design and test of a model-assisted participatory process for the formulation of a local climate adaptation plan. Clim Dev. https://doi.org/10.1080/17565529.2013. 812955 
Bagamba F, Bashaasha B, Claessens L, Antle J (2012) Assessing climate change impacts and adaptation strategies for smallholder agricultural systems in Uganda. Afr Crop Sci J ISSN 1021-9730/2012

Bornemann JF, Rowell DP, Evans B et al (2019) Future changes and uncertainty in decision-relevant measures of East African climate. Clim Chang. https://doi.org/10.1007/s10584-019-02499-2

Call M, Gray C, Jagger P (2019) Smallholder responses to climate anomalies in rural Uganda. World Dev. https://doi.org/10.1016/j.worlddev.2018.11.009

Carswell G (2002) Farmers and flowing: agricultural change in Kigezi District, Uganda. Geogr J. https://doi.org/ $10.1111 / 1475-4959.00043$

Christensen JH, Kumar KK, Aldrian E et al (2013) Climate phenomena and their relevance for future regional climate change. In: Stocker TF, Qin D, Plattner G-K et al (eds) Climate change 2013: the physical science basis. Contribution of Working Group I to the Fifth Assessment Report of the IPCC. Cambridge University Press, Cambridge

Coffel ED, Keith B, Lesk C et al (2019) Future hot and dry years worsen Nile Basin water scarcity despite projected precipitation increases. Earths Futur. https://doi.org/10.1029/2019EF001247

Collins M, Knutti R, Arblaster J et al (2013) Long-term climate change: projections, commitments, and irreversibility. In: Stocker TF, Qin D, Plattner G-K et al (eds) Climate change 2013: the physical science basis. Contribution of Working Group I to the Fifth Assessment Report of the IPCC. Cambridge University Press, Cambridge

Crerar S, Akurut M (2017) Advancing Uganda's NAP process in the water sector. Scoping field mission report. IISD Internal Unedited Document

Eder G, Fuchs M, Nachtnebel HP et al (2005) Semi-distributed modelling of the monthly water balance in an alpine catchment. Hydrol Process. https://doi.org/10.1002/hyp.5888

Gabiri G, Leemhuis C, Diekkrüger B, Näschena K, Steinbach S, Thonfeld F (2009) Modelling the impact of land use management on water resources in a tropical inland valley catchment of Central Uganda, East Africa. Sci Total Environ. https://doi.org/10.1016/j.scitotenv.2018.10.430

Geo-Ref.net (n.d.) Republic of Uganda. http:/wwwgeo-refnet/en/ugahtm. Accessed 1 June 2020

Giupponi C (2014) Decision support for mainstreaming climate change adaptation in water resources management. Water Resour Manag. https://doi.org/10.1007/s11269-014-0776-y

Grove AT (1996) African river discharges and lake levels in the twentieth century. In: Johnson TC, Odada EO (eds) The limnology, climatology, and paleoclimatology of the East African Lakes, Gordon and Breach Publishers, pp 95-100

Haile GG, Tang Q, Hosseini-Moghari S-M et al (2020) Projected impacts of climate change on drought patterns over East Africa. Earth's Future. https://doi.org/10.1029/2020EF001502

Harris I, Jones PD, Osborn TJ, Lister DH (2014) Updated high-resolution grids of monthly climatic observations - the CRU TS3.10 dataset. Int J Climatol. https://doi.org/10.1002/joc.3711

Hawkins E, Sutton R (2011) The potential to narrow uncertainty in projections of regional precipitation change. Clim Dyn. https://doi.org/10.1007/s00382-010-0810-6

Herrnegger M, Nachtnebel HP, Schulz K (2015) From runoff to rainfall: inverse rainfall-runoff modelling in a high temporal resolution. Hydrol Earth Syst Sci. https://doi.org/10.5194/hess-19-4619-2015

Herrnegger M, Senoner T, Nachtnebel HP (2018) Adjustment of spatio-temporal precipitation patterns in a high alpine environment. J Hydrol. https://doi.org/10.1016/j.jhydrol.2016.04.068

Hijmans RJ, Cameron SE, Parra JL, Jones PG, Jarvis A (2005) Very high resolution interpolated climate surfaces for global land areas. Int J Climatol. https://doi.org/10.1002/joc.1276

Kiem AS, Austin EK, Verdon-Kidd DC (2016) Water resource management in a variable and changing climate: hypothetical case study to explore decision making under uncertainty. J Water Clim Chang. https://doi.org/ $10.2166 /$ wcc. 2015.040

Kikoyo DA, Norbert J (2016) Assessment of impact of climate change and adaptation strategies on maize production in Uganda. Phys Chem Earth. https://doi.org/10.1016/j.pce.2015.09.005

Kizza CL, Tenywa MM, Majaliwa JGM et al (2017) Land use/cover change patterns in highland ecosystems of Lake Bunyonyi Catchment in western Uganda. Afr Crop Sci J. https://doi.org/10.4314/acsj.v25i1.4S

Kling H, Nachtnebel HP (2009) A method for the regional estimation of runoff separation parameters for hydrological modelling. J Hydrol. https://doi.org/10.1016/j.jhydrol.2008.10.015

Kling H, Stanzel P, Preishuber M (2014) Impact modelling of water resources development and climate scenarios on Zambezi River discharge. J Hydrol Reg Stud. https://doi.org/10.1016/j.ejrh.2014.05.002

Kling H, Stanzel P, Fuchs M et al (2015) Performance of the COSERO precipitation-runoff model under nonstationary conditions in basins with different climates. Hydrol Sci J. https://doi.org/10.1080/02626667.2014. 959956

Li J, Oyana TJ, Mukwaya PI (2016) An examination of historical and future land use changes in Uganda using change detection methods and agent-based modelling. Afr Geogr Rev. https://doi.org/10.1080/19376812. 2016.1189836 
Maclean IMD, Tinch R, Hassall M, Boar R (2003) Social and economic use of wetland resources: a case study from Lake Bunyonyi, Uganda (working paper). Centre for Social and Economic Research on the Global Environment, 1, 1-20. ISSN 0967-8875

Majaliwa MGJ, Barasa B, Mukwaya PI et al (2018) Assessing the extent of historical, current, and future land use systems in Uganda. Land. https://doi.org/10.3390/land7040132

McSweeney C, New M, Lizcano G (2010a). UNDP climate change country profiles: Uganda. https://www.geog. ox.ac.uk/research/climate/projects/undp-cp/UNDP_reports/Uganda/Uganda.lowres.report.pdf. Accessed 7 July 2020

McSweeney C, New M, Lizcano G, Lu X (2010b) The UNDP climate change country profiles improving the accessibility of observed and projected climate information for studies of climate change in developing countries. Bull Am Meteorol Soc. https://doi.org/10.1175/2009BAMS2826.1

Michelangeli A, Vrac M, Loukos H (2009) Probabilistic downscaling approaches: application to wind cumulative distribution functions. Geophys Res Lett. https://doi.org/10.1029/2009GL038401

Mileham L, Taylor RG, Todd M, Tindimugaya C, Thompson J (2009) The impact of climate change on groundwater recharge and runoff in a humid, equatorial catchment: sensitivity of projections to rainfall intensity. Hydrol Sci J. https://doi.org/10.1623/hysj.54.4.727

Nachtnebel HP, Baumung S, Lettl, W (1993) Abflußprognosemodell für das Einzugsgebiet der Enns und der Steyr. Report, Institute of Water Management, Hydrology and Hydraulic Engineering, University of Natural Resources and Applied Life Sciences, Vienna

Natugonza V, Ogutu-Ohwayo R, Musinguzi L et al (2016) Implications of climate warming for hydrology and water balance of small shallow lakes: a case of Wamala and Kawi, Uganda. Aquat Ecosyst Health Manag. https://doi.org/10.1080/14634988.2016.1142167

Niang I, Ruppel OC, Abdrabo MA et al (2014) Africa. In: Barros VR, Field CB, Dokken DJ et al (eds) Climate change 2014: impacts, adaptation, and vulnerability. Part B: regional aspects. Contribution of Working Group II to the Fifth Assessment Report of the Intergovernmental Panel on Climate Change. Cambridge University Press

Nicholson SE (1996) A review of climate dynamics and climate variability in eastern Africa. In: Johnson TC, Odada EO (eds) The limnology, climatology, and paleoclimatology of the East African Lakes. Gordon and Breach Publishers, pp 24-56

Osiru DSO (2006) Report on crop/farming systems and PRA. Prepared for FAO Transboundary agro-ecosystem management Programme (TAMP). Makerere University. http://www.fao.org/fileadmin/templates/nr/images/ resources/pdf_documents/kagera/uganda/ug_crop_farming_systems.doc. Accessed 3 August 2018

Rukundo B (2015) Ruhezamyenda catchment management plan, Part II: The Catchment Management Report. Prepared for Albert Water Management Zone, Ministry of Water and Environment, Uganda

Stanzel P, Kahl B, Haberl U et al (2008) Continuous hydrological modelling in the context of real time flood forecasting in alpine Danube tributary catchments. IOP C Ser Earth Environ. https://doi.org/10.1088/1755$1307 / 4 / 1 / 012005$

Stanzel P, Kling H, Bauer H (2018) Climate change impact on West African rivers under an ensemble of CORDEX climate projections. Clim Serv. https://doi.org/10.1016/j.cliser.2018.05.003

Sutcliffe JV, Parks YP (1999) The hydrology of the Nile. IAHS Special Publication 5. IAHS, Wallingford

Sutcliffe JV, Petersen G (2007) Lake Victoria: derivation of a corrected natural water level series. Hydrol Sci J. https://doi.org/10.1623/hysj.52.6.1316

Taylor KE, Stouffer RJ, Meehl GA (2012) An overview of CMIP5 and the experiment design. Bull Am Meteorol Soc. https://doi.org/10.1175/BAMS-D-11-00094.1

Trabucco A, Zomer RJ (2009) Global Aridity Index (Global-Aridity) and Global Potential Evapotranspiration (Global-PET) Geospatial Database. http://wwwcsicgiarorg. Accessed 20 August 2018

Vrac M, Drobinski P, Merlo A, Herrmann M, Lavaysse C, Li L, Somot S (2012) Dynamical and statistical downscaling of the French Mediterranean climate: uncertainty assessment. Nat Hazards Earth Syst Sci. https://doi.org/10.5194/nhess-12-2769-2012

Vrac M, Noël T, Vautard R (2016) Bias correction of precipitation through singularity stochastic removal: because occurrences matter. J Geophys Res Atmos. https://doi.org/10.1002/2015JD024511

Wilby RL (2005) Uncertainty in water resource model parameters used for climate change impact assessment. Hydrological Processes 19:3201-3219. https://doi.org/10.1002/hyp.5819

Wilby RL, Dessai S (2010) Robust adaptation to climate change. Weather. https://doi.org/10.1002/wea.543

Publisher's note Springer Nature remains neutral with regard to jurisdictional claims in published maps and institutional affiliations. 